Research Article

\title{
The long-term stability of residual stresses in steel
}

\author{
Eckehard Mueller ${ }^{1,2}$ (1)
}

Received: 2 September 2021 / Accepted: 5 November 2021

Published online: 18 November 2021

(c) The Author(s) $2021 \quad$ OPEN

\begin{abstract}
There is frequent debate over the long-term stability of calibration specimens. It is an essential component of monitoring, especially for X-ray diffraction equipment used to determine residual stresses. If residual stresses are stable, a second consideration is that the residual stress should not be close to $0 \mathrm{MPa}$. If such specimens are available for monitoring, it is more sensitive concerning changes. These are key requirements when developing calibration specimens. In this study five specimens were observed, one of them was tested for more than 20 years. The stresses were determined with X-ray diffractometers. In the last four years two different X-ray methods for determination were used. It can be shown that high compressive residual stress does not change in steel if the specimens had no dynamic or static load and were stored under normal laboratory conditions.
\end{abstract}

\section{Article Highlights}

- Finding a material in which compressive residual stress is stable
- Showing that the stability of compressive residual stress is over a long term

- The stability of the compressive residual stress is in a great range

Keywords Residual stress · Stress relaxation · Long term stability · Experimental techniques

\section{Introduction}

Compressive residual stress is often built up in the surface layers of a component to enhance its durability because it can delay or suppress the propagation of cracks. Compressive residual stress can be induced using different methods, popular ones being mechanical surface treatments like shot peening or deep rolling [1-3]. It has been found that under higher dynamic loads the compressive residual stress reduces. However, the possibility of stress relaxation in components occurring under no load has not been examined often [4], and no studies have reported on the long-term (i.e., over years) stability of compressive residual stress.

Stresses in Almen strips relax within minutes after peening [4]. If after minutes residual stresses are stable it allows calibrating and monitoring X-ray diffractometers, which is very important. The hole-drilling method is traditionally used to determine residual stress. Strain gauges are fixed to the surface and move when drilling into the material commences. From the recorded movement in the strain gauges, the residual stress can be calculated. The disadvantage is that no measurement at the surface is possible, and the strain gauges cannot be used a second time. Before measurements a calibration is not possible using

Eckehard Mueller, eckehard.mueller@hs-bochum.de | 'Bochum University of Applied Sciences, Bochum,

Germany. ${ }^{2}$ Steinbeis-Transfercenter for Spring Technology, Component Behavior and Process, Iserlohn, Germany.

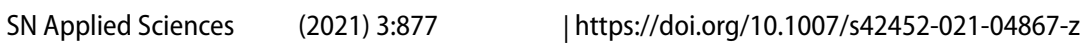


this method. Consequently, X-ray diffraction is becoming the standard method for calibration (see Sect. 4 for a description of this method). Measuring strain by X-ray diffraction is non-destructive at the surface, making it possible to monitor the stability of the equipment and calibrate it with specially designed specimens. This is only possible if the residual stress in the material is stable, but once this condition is met mechanical surface-treated specimens can be easily produced and used.

In this study we aimed to examine the stability of residual stress in steel. The investigation arises from monitoring the X-ray equipment in the accredited laboratory of the Steinbeis-Transfercenter for Spring Technologies, Component Behavior and Process in Germany. All data available the time before 2007 were also involved because the measurement conditions had not changed.

At first in this article the specimens were described to know in which material compressive residual stresses are stable. In the second step the measurement technique will be explained because it is new method for X-ray diffraction. Afterwards the results are shown from 2000 to the present (2020) and the consequences calibration of X-ray diffraction equipment is short discussed.

\section{Status of research}

The compressive residual stress reduces under a cycle load but after a certain number of cycles it becomes constant. The main variables affecting compressive residual stress are shown and also the limit of residual stresses [5]. In [6] it is reported that a cold-drawn prestressed wire has a significant reduction in the induced compressive residual stresses by cyclic overloading. Depending on the load which was between 0.75 and 1.25 times the yield strength the experiment shows different reduction amounts. The higher the loading the more reduction is achieved up to more than $80 \%$. There are two questions arising from these results, which are still open. Is the residual stress constant over a long time period? Is it independent of the amount of residual stresses in the specimen? To answer this question specimens with strong compressive residual stresses were measured with several different $\mathrm{X}$-ray diffractometers to monitor the development of residual stresses at each specimen. Several diffractometers were used at the same time to detect a shift of one diffractometer.

\section{Specimens}

\subsection{Description of the Specimens}

Five different specimens were used in this investigation (Table 1). Specimens 1 and 2 were identical and were named KP1 (calibration probe, in German: Kalibrierprobe 1) and KP2. Figure 1 shows these specimens, and they had the dimensions $60 \times 60 \times 9 \mathrm{~mm}$. They were made of $50 \mathrm{CrV}$ 4 (1.8159) steel, with a tensile strength of $1600 \mathrm{MPa}$ after tempering. Subsequently, the specimens were ground to avoid decarburization.

An area of $55 \times 55 \mathrm{~mm}$ was deep rolled in the shape of a meander to obtain high compressive residual stresses. The area was very smooth at the surface, with a roughness $R_{z}$ between 5 and $13 \mu \mathrm{m}$. The deep rolling parameters were optimized to obtain the maximum compressive residual stress at the surface which was slightly over $-900 \mathrm{MPa}$ [7]. The specimens have been in use since 2015, the year of manufacture.

Specimen 3 was called GKN because it was used in a round-robin test in 2008 organized by Mr. Lietzau at GKN Germany [8]. Figure 2 shows this specimen, which has dimensions of $50 \times 30 \times 10 \mathrm{~mm}$. It is an unalloyed Q\&T steel Cf53 (1.1213) which was inductive surface hardened and tempered for $30 \mathrm{~min}$ at $180^{\circ} \mathrm{C}$. After this process, the surface area was ground. The residual stress at the surface was approximately $-350 \mathrm{MPa}$. This specimen was manufactured in 2005/2006.

Specimen 4 is referred to as $D+N$ because it is a torsion bar that was produced by Dittmann and Neuhaus in Germany. Its dimensions are $180 \mathrm{~mm}$ long $\times 60 \mathrm{~mm}$ diameter (Fig. 3). It is made of steel $56 \mathrm{Ni} \mathrm{Cr}$ Mo V 4 (1.7701) with a tensile strength of $2000 \mathrm{MPa}$ and was shot-peened. Its residual stress is about $-500 \mathrm{MPa}$ in $100 \mu \mathrm{m}$ depth. The specimen was manufactured in 2000 and is in use since this time to monitor $\mathrm{X}$-ray diffractometers.

Specimen 5 is known as M13-16. It is similar to Specimen 4, except that it is slightly longer at $200 \mathrm{~mm}$ length, and it was manufactured in the beginning of 2016 (Fig. 3).
Table 1 Specimen characteristics

\begin{tabular}{lllll}
\hline Specimen & Name & Material & Treatment & Manufacturing year \\
\hline 1 & KP1 & 50 Cr V 4 & Deep rolled & 2015 \\
2 & KP2 & 50 Cr V 4 & Deep rolled & 2015 \\
3 & GKN & Cf 53 & Inductive hardened & $2005 / 2006$ \\
4 & D + N & 56 Ni Cr Mo V 4 & Shot peened & 2000 \\
5 & M13-16 & 56 Ni Cr Mo V 4 & Shot peened & 2016 \\
\hline
\end{tabular}


Fig. 1 Deep rolled specimen KP1 and KP 2. The measuring direction was perpendicular to the tracks

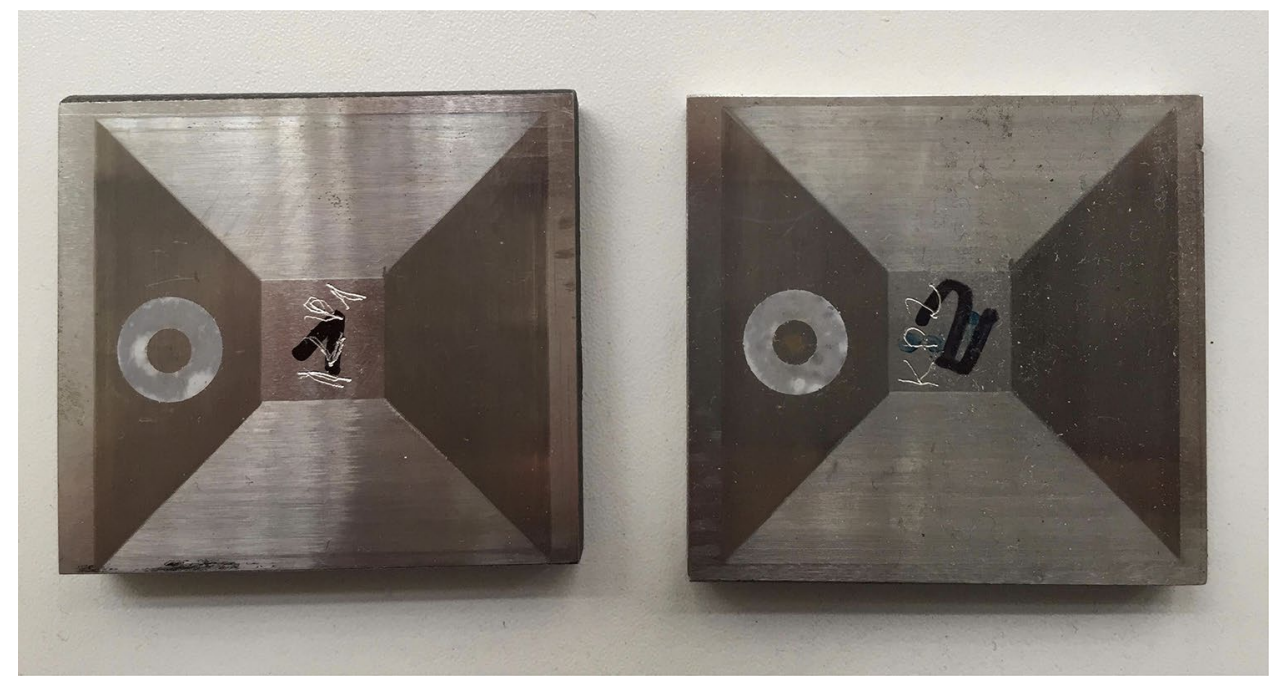

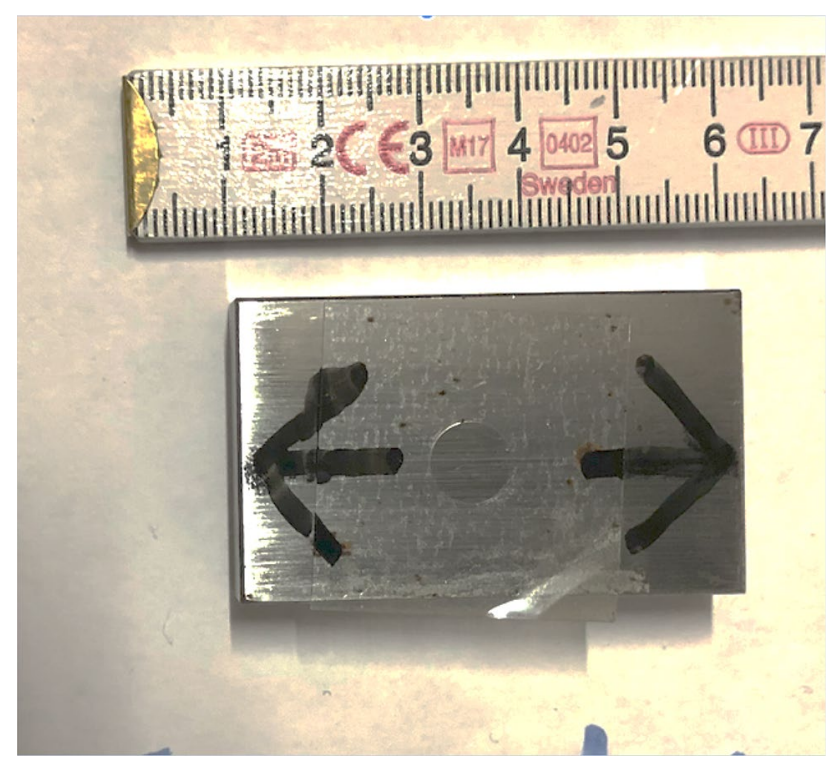

Fig. 2 Specimen GKN with the measurement direction like the arrows

The situation of the residual stress is the same compared to specimen 4.

All data of the specimen are summarized in Table 1:

\subsection{Storage of the specimenes}

All specimens were stored in the laboratory at temperatures between 10 and $30^{\circ} \mathrm{C}$. The humidity was in the normal range $(60-70 \%)$. The specimens were stored in a wooden cabinet and there were no additional storage precautions taken. The specimen GKN was lent to the Institute for Metallurgy in Komsomolsk, Siberia, in February and March 2015. This specimen had a higher temperature range.

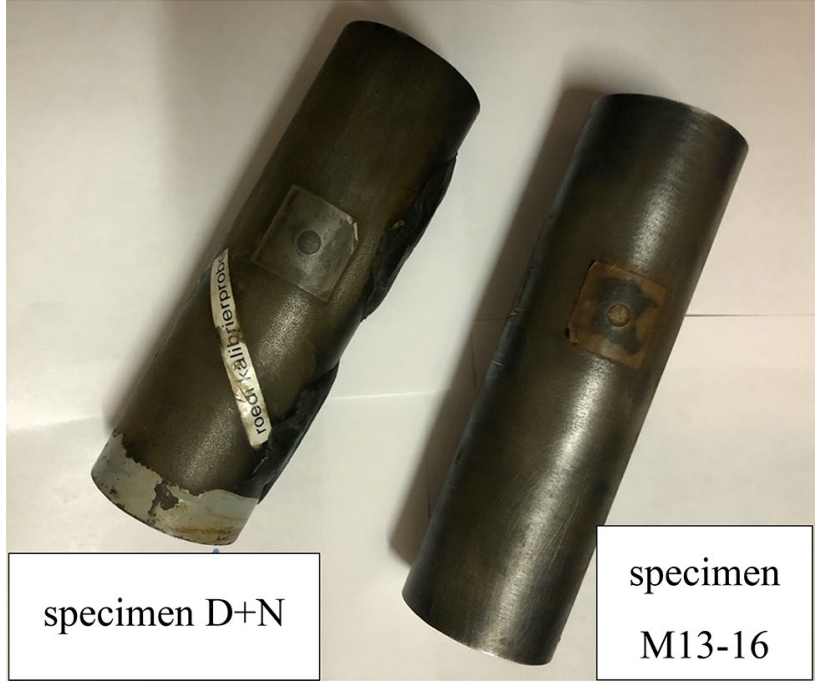

Fig. 3 Shot peened specimen $\mathrm{D}+\mathrm{N}$ and $\mathrm{M} 13-16$. The measuring direction was along the bar

\section{Description of the X-ray diffractometer methods and equipment}

Both of the methods to determine residual stresses are based on Bragg's law. The incident X-rays are reflected at different atomic layers lying in the same direction and, if the reflected $\mathrm{X}$-rays have the same phase, constructive interference will appear, and a signal is detected. It is only possible to obtain constructive interference at a special angle $\psi$ (Fig. 4). With some geometrical constraints you get the following formula:

$2 d \sin \psi=\lambda$ 


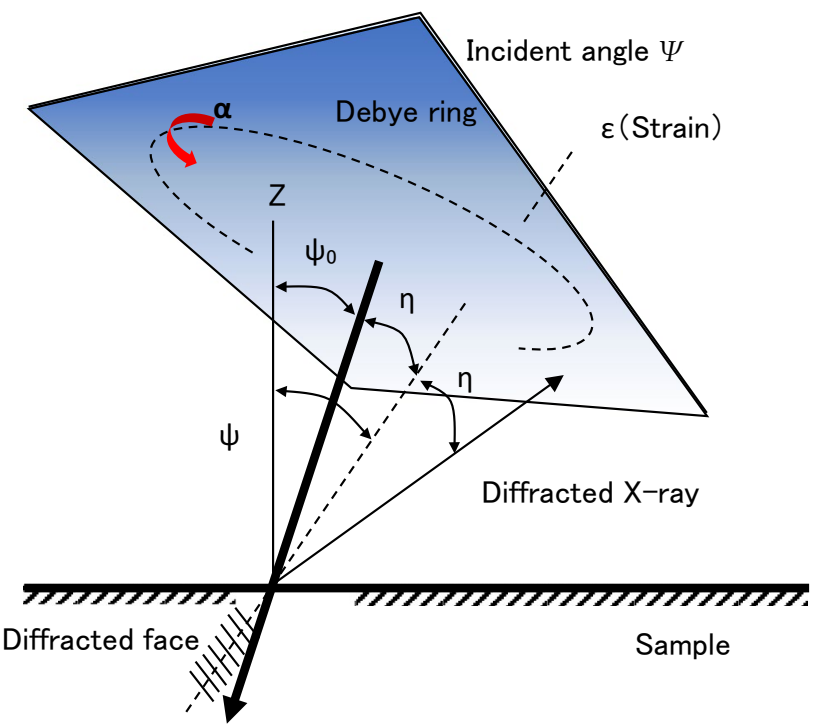

Fig. 4 Arrangement for the cos-a-method used to measure the distance of the atomic layers

where $\lambda$ is the wavelength of the X-rays which is known, and $d$ is the spacing of the atomic layers (e.g. [9]).

The change in distance delta d proportional to the macroscopic strain $\varepsilon$. Stress can be calculated using the E-module $E$ and the Poisson's ratio $v$. This means that the residual stress cannot be measured directly and is only determined using calculations.

Every $\mathrm{X}$-ray diffraction gives a fully reflected ring at the angle $\psi$, which is known as a Debye-Scherrer ring if the material has a polycrystal structure (Fig. 4). Depending on the amount of strain there is, the angle $\psi$ varies and the whole ring is shifted. Now two methods based on the Debye-Scherrer ring are described which were used in practice.

\subsection{Cos-a-method}

The cos-a-method is new and is not yet very popular. Even so, a brief introduction is provided to it here. There is one incident angle, $\psi_{0}$ and a whole ring shift is used $[10,11]$. Figure 4 illustrates the situation.

The shift's (see Fig. 5) dependence on the rotating angle $a$ is as follows:

$\sigma_{x}=-\frac{E}{1+v} \frac{1}{\sin 2 \eta} \frac{1}{\sin \Psi_{0}}\left(\frac{\partial \varepsilon \alpha 1}{\partial \cos \alpha}\right)$

with the shift $\varepsilon \alpha 1$ of the Debye ring defined in (3):

$\varepsilon \alpha 1=\frac{1}{2}\left(\left(\varepsilon_{\alpha}-\varepsilon_{\pi+\alpha}\right)+\left(\left(\varepsilon_{-\alpha}-\varepsilon_{\pi-\alpha}\right)\right)\right.$

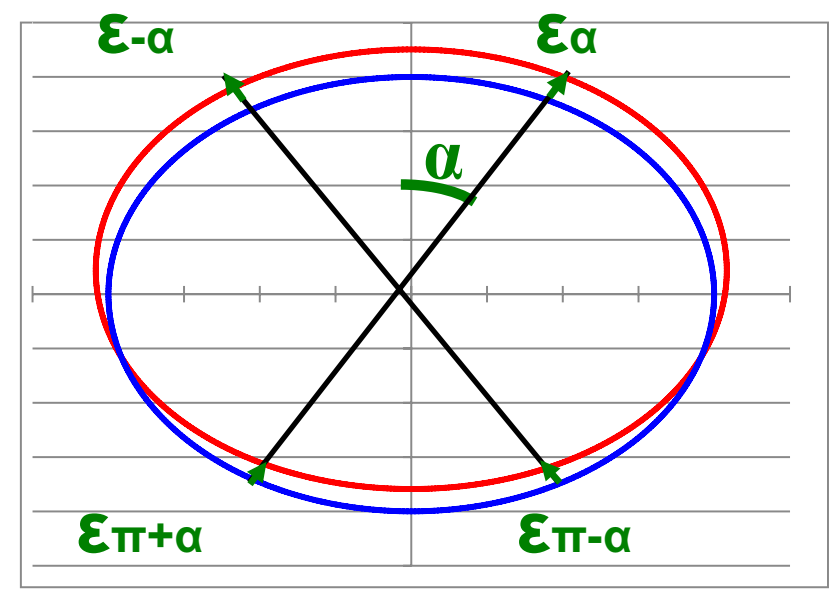

Fig. 5 Shift of the Debye-Scherrer ring and the variables required to calculate it

and $\sigma_{x}$ the obtained residual stress in the measurement direction, a the rotation angle of the ring, $E$ the $E$-Modul, $\checkmark$ Poisson ratio. $\psi$ is the incidence angle and $2 \eta$ the angle between the incident and reflected beam. All variables are presented in Fig. 5.

By determining the linear slope (last term in the Eq. (2)), the stress can be calculated.

For this kind of measurement, an X-ray diffractometer (pulstec $\mu-X 360 s$ ) operating by means of cos- $\alpha-m e t h o d$ with an incident angle $\psi_{0}=35^{\circ}$ was used. For steel, $\mathrm{Cr}-\mathrm{K}_{\mathrm{a}}$ radiation is in use at nearly all $\mathrm{X}$-ray diffractometers that is also the case of these measurements described here. The setup which was used is shown in Fig. 6. This diffractometer has been in use since 2016.

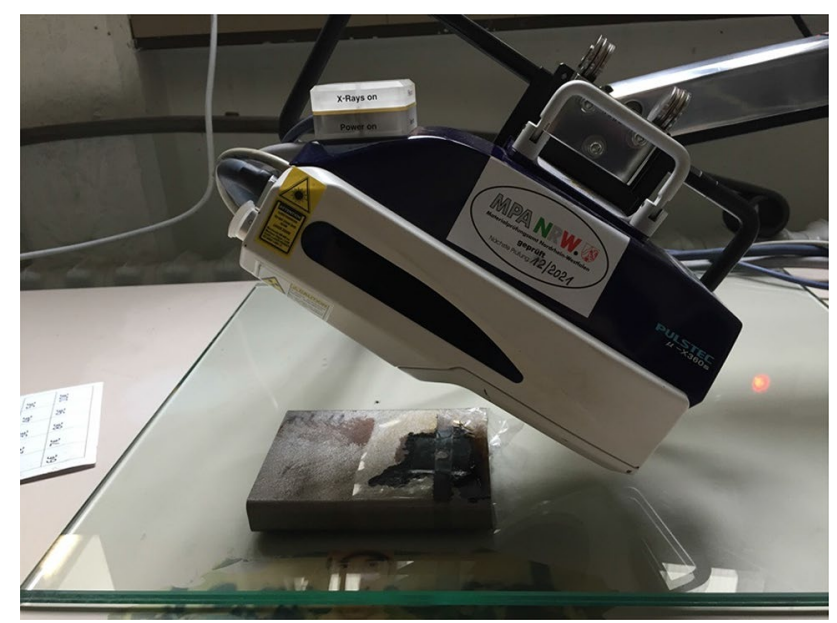

Fig. 6 A $\mu$-X360s diffractometer 


\section{2 $\operatorname{Sin}^{2} \Psi-2 \theta$-method}

The $\sin ^{2} \psi-2 \theta$-method detects only a small section of the Debye-Scherrer ring and uses different incident angles $\psi$ (different shifts) to determine the residual stress. Layers with different orientations to the strain are sensitive to different incident angles. The spacing of these layers is proportional to $\sin ^{2} \psi$. The formula to calculate stress using this method is as follows.

$\varepsilon=\frac{1+v}{E} \sin ^{2} \psi+$ const

where $\varepsilon$ is the strain, $E$ is the specific diffraction plane elastic modulus and $v$ is the Poisson's ratio.

This is the traditional method used to determine residual stress by X-ray diffraction. Good descriptions are found in $[12,13]$. For this method, several diffractometers of the type Rigaku Strainflex MFS-2 M were used (Fig. 7). They were manufactured between 1982 and 1988 and maintained by Rigaku based in Japan and later by the lab staff in the same way. A total of five different devices of this type were available during different time periods, because spare parts were not available to repair the old one.

\subsection{Comparison of the methods}

The relevant measurement parameters of the two methods are summarized in Table 2.

Table 3 shows the existing literature concerning the use of the equivalence of both methods in relation to different materials. The comparison was done in some cases with tensile load stress and in other cases with compressive residual stress. In this case the experiment was performed with compressive residual stresses. Due to this, the measured values from different $\mathrm{X}$-ray diffractometers and methods can be averaged for further investigation.

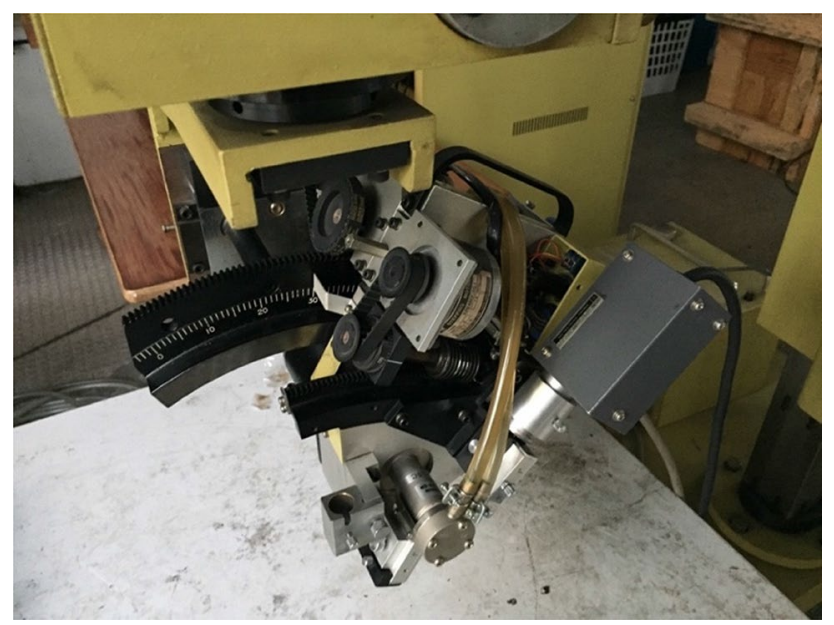

Fig. 7 Goniometer of MFS-2 M
Table 2 Relevant measurement parameters

\begin{tabular}{lll}
\hline Method & $\sin ^{2} \psi-2 \theta$ & cos-a \\
\hline equipment & Rigaku MFS-2 M & pulstec $\mu-X 360 \mathrm{~s}$ \\
measuring spot & $8 \mathrm{~mm}$ & $4 \mathrm{~mm}$ \\
radiation & $\mathrm{Cr}-\mathrm{Ka}$ & $\mathrm{Cr}-\mathrm{Ka}$ \\
incident angle(s) & $0^{\circ}$ to $\left.45^{\circ}{ }^{*}\right)$ & $35^{\circ}$ \\
detector & scintillator & $\mathrm{MAD}$ \\
E-Modulus & $210,000 \mathrm{MPa}$ & $210,000 \mathrm{MPa}$ \\
Possion's ratio & 0.3 & 0.3 \\
Measured plane & {$[211]$} & {$[211]$} \\
tube current & $10 \mathrm{~mA}$ & $1,5 \mathrm{~mA}$ \\
fitting & Lorenz & Lorenz \\
measuring time & $15 \mathrm{~min}$ & $5 \mathrm{~s}$ \\
measurement error & $7 \%$ & $7 \%$ \\
(standard deviation) & & \\
\hline
\end{tabular}

${ }^{*}$ At least 5 angles

\section{Measurements and results}

Formula (2) is simplified. If shear stress exists, it must be eliminated by measuring in the positive $\psi$ and negative $\psi$-direction $[12,13]$. From the two results, the mean is calculated to eliminate the shear stress. Therefore, measurements were made in both directions, and this procedure was carried out for both methods.

The measurement error (standard deviation) of both diffractometers was approximately $30 \mathrm{MPa}$ below the border of $\pm 400 \mathrm{MPa}$ and for a greater amount $7 \%$. This error is the statistical error of a single measurement. A time grid of a quarter of a year was chosen for the analysis (see Appendix).

All diffractometers which were available were involved to reduce the risk of drift from a single device. The first measurement with one specimen was done in 2000 to monitor a diffractometer. Since 2007 the laboratory is

Table 3 The materials in the reviewed literature

\begin{tabular}{ll}
\hline Material & References \\
\hline 50 Cr V 4 (1.1859) & {$[6,14]$} \\
martensitic steel & {$[15]$} \\
JJ SS400 & {$[11]$} \\
C1018 (AISI 1018) & {$[16]$} \\
Platinum & {$[17]$} \\
SUS316. (1.4404) & {$[18]$} \\
IN718 & {$[18]$} \\
42 Cr Mo V 4 (1.7225) & Internal investigation *) \\
ST 52-3 (1.0570) & Internal investigation *) \\
FD SiCr 6 & Internal investigation *) \\
\hline
\end{tabular}

*The data bases of an internal investigation of the Spring Technology, Component Behavior and Process and has not been published yet 
accredited (DIN 17025) which means that the monitoring must be done. in shorter intervals. Over time, more machines were positioned in the lab, while others were taken away if they malfunctioned. Additional specimens were used during this time. If the specimens were measured with different devices, a mean value was calculated (gray fields, see Appendix).

Figure 8 shows the development of the residual stresses of specimens over the investigated period. The $x$-axis shows the different absolute years in which the measurements were one. The $y$-axis represents the scale of the obtained residual stresses. Note that it is always compressive stress (negative sign). The specimen $\mathrm{D}+\mathrm{N}$ was measured for the longest time. Within the errors, the compressive residual stress remains constant. The variation of the single values is caused by the measurement errors (see previous paragraphs). The values are based on the results in the appendix. The single results were connected by a line to see the related points. In the first period the measurement was done occasionally, because the important question of stability arises around 2010 in the scientific community.

Specimens KP1 and KP 2 which had the highest compressive residual stresses were the most sensitive samples concerning a reduction in residual stress. The stress is constant within the errors, and no trend is seen for all specimens. The variations are caused by the measurement errors. E. g. a linear fit taking the values from sample $D+N$ (oldest) gives a slope of $\mathrm{m}=-1.81 \times \mathrm{t}$ (time in absolute years, not the difference of the years), which means there was a calculated slight increase in the compressive residual stress of $36 \mathrm{MPa}$ in 20 years, the lifetime of the sample. Specimen GKN had a slope of $m=2.49$, meaning there was a decrease in compressive residual stress of $25 \mathrm{MPa}$ over 10 years (lifetime of the sample). These changes are not significant and within the measurement errors (standard deviation of the Gaussian distribution). The specimens were stored as mentioned above in a normal laboratory

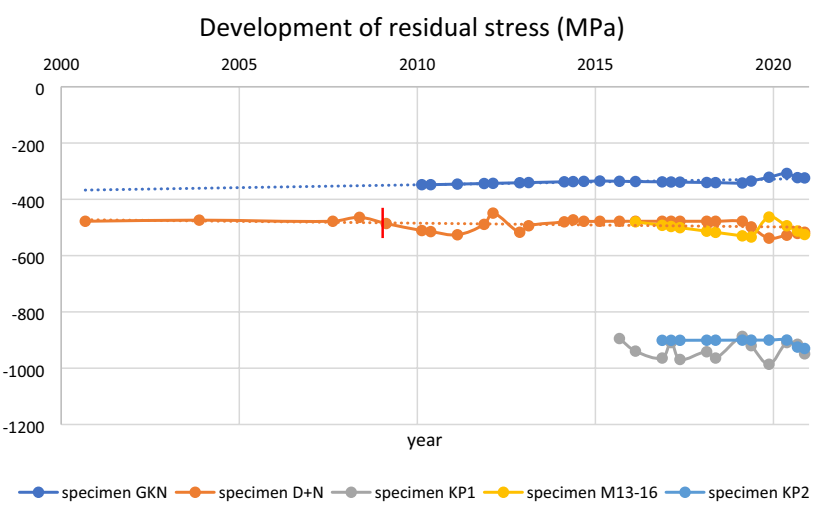

Fig. 8 Development of compressive residual stress over the course of the investigation with two linear fits $(D+N, G K N)$ environment. As a result, no reduction of compressive residual stresses at different levels can be seen.

The inducing stresses in the specimens creates dislocations with different spacing of the atomic layers in the lattice. This fact can be seen that the reflected beam intensity has a distribution in the reflected angle and is not sharp. The widening of the distribution is an indication of the number of dislocations. The dislocations are created under high selective mechanical pressure (shot peening, deep rolling) which means with a high amount of energy. At high compressive residual stresses at these materials, more dislocation move to the border of a grain and the position are stabilized there $[7,10]$. The elimination of these dislocations cannot be done by thermal energy at room temperature.

\section{Using specimens for calibration}

To change from a monitoring specimen to a calibration specimen, a round-robin test must be done. There is no national or international standard available like with SI units ( $\mathrm{m}$, $\mathrm{kg}$, etc.). Specimen KP1 and KP2 were obtained from a large round-robin test that involved 30 laboratories. The test was organized as mentioned above by Mr. Lietzau of GKN, Germany. All laboratories used the $\sin ^{2} \psi-2 \theta$-method because at this time the cos-a-method was not available.

The values of KP1 and KP2 were $-934 \mathrm{MPa}$ and $-926 \mathrm{MPa}$, respectively. Both samples had an systematic uncertainty of $\pm 50 \mathrm{MPa}$ or $5.4 \%$, which are the best value available in public at the moment $[14,19]$. Also, all roundrobin test results are listed in $[14,19]$ which was done in public the last 20 years.

\section{Conclusion}

It was shown that the compressive residual stress in steel induced by mechanical surface treatment does not change over long time periods of more than 20 years if the specimen is stored under normal room conditions. It is unlikely that more extreme storage conditions would impact the compressive residual stress of materials, but it was not tested here.

Such specimens can also be used for long-term monitoring of X-ray diffractometers. If the samples (like KP1 and $\mathrm{KP} 2$ ) are related to a round-robin test it can be used as a calibration sample. Using a high amount of compressive residual stress is possible and this would not be expected to reduce over time.

The compressive residual stresses induced by shot peening and deep rolling affect corrosion positively $[20,21]$. Pitting resistance is significant improved by compressive 
residual stresses [22, 23]. Also, cavitation is delayed [24, 25]. In many cases no dynamic load respectively stress is on a component affected by corrosion. This means, the change of the induced residual stresses is only caused by corrosion or cavitation itself during the operation time. The compressive residual stress can be implemented in such a component long before using it and can be stored over a long time.

Funding Open Access funding enabled and organized by Projekt DEAL.

\section{Declarations}

Conflict of interest There is no conflict of interest in any way concerning this article.

Open Access This article is licensed under a Creative Commons Attribution 4.0 International License, which permits use, sharing, adaptation, distribution and reproduction in any medium or format, as long as you give appropriate credit to the original author(s) and the source, provide a link to the Creative Commons licence, and indicate if changes were made. The images or other third party material in this article are included in the article's Creative Commons licence, unless indicated otherwise in a credit line to the material. If material is not included in the article's Creative Commons licence and your intended use is not permitted by statutory regulation or exceeds the permitted use, you will need to obtain permission directly from the copyright holder. To view a copy of this licence, visit http://creativeco mmons.org/licenses/by/4.0/.

\section{Appendix}

The numerical data used for the analysis. All values are in $\mathrm{MPa}$. After the numeric year, the quarter $(\mathrm{Q})$ within the year is given See Table 4.
Table 4 Numerical data of the obtained residual stresses (MPa)

\begin{tabular}{|c|c|c|c|c|c|}
\hline Year & specimen GKN & specimen $\mathrm{D}+\mathrm{N}$ & specimen KP1 & $\begin{array}{l}\text { specimen } \\
\text { M13-16 }\end{array}$ & specimen KP2 \\
\hline 2000 Q3 & & -478 & & & \\
\hline 2003 Q4 & & -474 & & & \\
\hline 2007 Q3 & & -478 & & & \\
\hline 2008.Q3 & & -464 & & & \\
\hline 2009 Q1 & & -486 & & & \\
\hline 2010 Q1 & -348 & -511 & & & \\
\hline 2010 Q3 & -348 & & & & \\
\hline 2011 Q1 & & -526 & & & \\
\hline 2011 Q4 & & -489 & & & \\
\hline 2012. Q1 & & -449 & & & \\
\hline 2012 Q4 & & -517 & & & \\
\hline 2013 Q1 & & -494 & & & \\
\hline 2014 Q1 & & -480 & & & \\
\hline 2014.Q3 & & -473 & & & \\
\hline 2014.Q4 & & -478 & & & \\
\hline 2015. Q1 & $\left.-335^{*}\right)$ & & & & \\
\hline 2015 Q3 & & & -895 & & \\
\hline 2016 Q1 & & & -939 & -480 & \\
\hline 2016 Q4 & & & -964 & & -901 \\
\hline 2017 Q1 & & & -909 & & \\
\hline 2017 Q2 & & & -969 & & \\
\hline 2018 Q1 & & & -942 & & \\
\hline 2018 Q2 & & & -964 & & \\
\hline 2019 Q1 & -342 & -478 & -887 & & \\
\hline 2019 Q3 & & & & -534 & \\
\hline 2019 Q4 & & -538 & -986 & -463 & \\
\hline 2020.Q2 & -308 & & -909 & & -900 \\
\hline 2020 Q3 & -323 & & -915 & & -925 \\
\hline 2020 Q4 & -324 & -517 & -949 & -525 & -930 \\
\hline
\end{tabular}

Bold values are a mean value of at least two different diffractometers.

*Measured in Komsomolsk 


\section{References}

1. Baiker S (ed) (2017) Shot peening - a dynamic application and its future, 5th edn. MFN, Wetzikon, Switzerland

2. Scholtes B (ed) (1991) Eigenspannungen in mechanischen randschichtverformten Werkstoffzuständen DGM Informationsgesellschaft $\mathrm{GmbH}$. Oberursel, Germany

3. Schulze V (ed) (2005) Shot peening and other mechanical surface treatments. Transfer Series, II Technology, IITT-International, Noisy-le-Grand France

4. Lang KH (2020) Room temperature stress relaxation of a quenched and tempered steel in challenges in mechanics of time dependent materials, vol 2. Springer, Cham, Switzerland

5. Torres MAS, Voorwald HJC (2002) An evaluation of shot peening, residual stress and stress relaxation on the fatigue life of AISI 4340 steel. Inter J Fatigue 24(8):877-886

6. Toribio J, Lorenzo M, Vergara D, Aguado L (2017) The role of overloading on the reduction of residual stress by cyclic loading in cold-drawn prestressing steel wires. Appl Sci 7:84. https:// doi.org/10.3390/app7010084

7. Müller E (2017) Röntgenografische eigenspannungsmessungen -Vergleich zweier methoden. In Fortschritte in der Werkstoffprüfung für Forschung und Praxis FH, Langer JB, (Eds). Deutscher Verband für Materialforschung und -prüfung e. V.: Berlin , Germany, pp 147-150

8. Lietzau J (2008) Ringversuch Eigenspannungen zur Erzeugung von spannungsbehafteten ILQ-Referenzproben. presentation given at AWT FA13 Eigenspannungen, Freiburg, Germany, 29.04.2008.

9. Halliday D, Resnik R, Walker J (2014) Fundamental of physics, 10th edn. Wiley, Hoboken, USA

10. Ramirez-Rico J, Lee SY, Ling JJ, Noyan IC (2016) Stress measurement using area detectors. a theoretical and experimental comparison of different methods in ferritic steel using a portable X-ray apparatus. J Mat Sci 51:5343-5355. https://doi.org/ 10.1007/s10853-016-9837-3

11. Sasaki T (2014) New generation X-ray stress measurement using debye ring image data by two-dimensional detection. Mater Sci Forum 783-786:2103-2108

12. He BB (2018) Two -dimensional X-ray diffraction, 2nd edn. Wiley, Hoboken, USA

13. Spieß L, Teichert G, Schwarzer R, Behnken H, Genzel C (2019) Moderne Röntgenbeugung, 3rd edn. Springer Spektrum, Wiesbaden, Germany

14. Müller E (2019) Precision of the residual stress determined by $\mathrm{X}$-ray diffraction: summery and limits. Surfaces 7:8
15. Delbergue $D$, Texier $D$, Lévesque $M$, Bocher $P$ (2016) Comparison of two X-ray residual stress measurement methods: $\operatorname{Sin}^{2} \psi$ and $\operatorname{Cos} a$, through the determination of a martensitic steel X-ray elastic constant. Mat Res Proceed 2:55-60. https://doi.org/10. 21741/9781945291173-10

16. Lee SY, Ling JJ, Wang S, Ramirez-Rico J (2017) Precision and accuracy of stress measurement with a portable $X$-ray machine using an area detector. J Appl Crystals 50:131-144. https://doi.org/10. $1107 /$ S1600576716018914

17. Ling J, Lee SY (2017) Characterization of a portable x-ray device for residual stress measurements. Adv X-ray Anal 59:153-161

18. Kohri A, Takaku J, Nakashiro M (2016) Comparison of X-ray residual stress measurement values by Cos a method and $\operatorname{Sin}^{2} \psi$ method. Mat Res Proceed 2:103-108. https://doi.org/10.21741/ 9781945291173-18

19. Mueller E (2016) How precise can be the residual stress determined by X-ray diffraction? A summary of the possibilities and limits. Mat Res Proceed 2:295-298. https://doi.org/10.21741/ 9781945291173-50

20. Gharbi K, Moussa NB, Fred NB (2018) Corrosion resistance enhancement of AISI 304 stainless steel by deep rolling treatment. International Conference on Advances in Mechanical Engineering and Mechanics. Springer: Cham, Germany, pp 233-239

21. Gujba AK, Medraj M (2014) Laser peening process and its impact on materials properties in comparison with shot peening and ultrasonic impact peening. Materials 7(12):7925-7974. https:// doi.org/10.3390/ma7127925

22. Peyer $P$, Scherpereel $X$, Berthe $L$, Carboni $C$, Fabbro R, Lemaitre $C$ (2000) Surface modification induced in $316 \mathrm{~L}$ steel by laser peening and shot-peening: influence of pitting corrosion. Mat Sci Eng 280:294-302

23. Qiao M, Hu J, Guo K, Wang Q (2020) Influence of shot peening on corrosion behavior of low alloy steel. Mat Res Express 7(1):01657. https://doi.org/10.1088/2053-1591/

24. Muñoz-Cubillos J, Coronado JJ, Rodríguez SA (2019) On the cavitation resistance of deep rolled surfaces of austenitic stainless steels. Wear 428:24-31

25. Rao AS (1999) Influence of surface finish on cavitation erosion. Hydro's Future'99, Technology, Markets, and Policy, Las Vegas; Brookshier, P. E. Ed., ASCE: Reston, USA, pp 1-9. https://doi.org/ 10.1061/9780784404409

Publisher's Note Springer Nature remains neutral with regard to jurisdictional claims in published maps and institutional affiliations. 